\title{
Evaluation on the Consumer Credit in Returns Reverse Logistics
}

\author{
Donghong Yang, Wenyan Duan \& Yanbin Sun \\ School of Economics and Management \\ Daqing Petroleum Institute \\ Daqing 163318, China \\ Hui Li \\ Daqing Oilfield \\ Daqing 163318, China \\ E-mail: dqyangdonghong@126.com
}

\begin{abstract}
In buyers' market, the returns reverse logistics caused by consumer credit can increase the management costs that enterprises spend dealing with the reverse logistics, and it can also cause bad community atmosphere. Based on the consumer's gender, age, education, occasion, position and the average monthly income, this paper establishes index system to evaluate consumer credit and uses Fischer discrimination II to measure the credit level of consumers, which provides a reference for enterprises to establish a scientific assessment system to evaluate the consumer credit.
\end{abstract}

Keywords: Returns reverse logistics, Consumer credit, Fisher discrimination II

\section{Introduction}

The return goods are the most common in the reverse logistics, and the returns reverse logistics caused by the consumer credit takes up high proportion, which seriously affects the profits and reputation of enterprises. Therefore, more and more enterprises are beginning to know the importance of evaluating the consumer credit.

\section{Constructing the index system of consumer credit evaluation}

Constructing the index system of consumer credit must agree with the principles such as scientific, systematic comprehensive, predictable, quantifiable, flexible and operational, and comprehensively consider the factors of credit evaluation. Then based on the classifying, collecting and sorting out, we can determine the input indexes as Table 1.

\section{Insert Table 1 here}

\section{The questionnaire of consumer credit}

This paper uses scoring list to create the score model of qualitative indexes to determine an evaluation criteria program of qualitative indexes. It uses 5-point score to give the score, the greater the score, the smaller the individual credit risk. In addition to the score standard, specific points and division levels refer to the methods in the practice.

\section{Insert Table 2 here}

According to the basic request of scoring list, we determine the scoring criteria of each evaluation factor, and then calculate the total score. The greater the total score, the smaller the credit risk and the better the individual credit.

This paper uses questionnaire method to collect the parameters of consumers' credit indexes. Through sorting out, there are 40 valid questionnaires, and good credit's and bad credit's are separately 20 . The result of questionnaires is showed as Table 3 . The category 1 stands for the consumers of good credit and the category 2 stands for the ones of bad credit. $\mathrm{C}$ is short for Category; $\mathrm{M}$ is short for Marriage; I is short for Income.

\section{Insert Table 3 here}

According to the scoring list, we score the consumer credit evaluation questionnaire to calculate conveniently and the result is showed as Table 4 (C, G, A, E, O, P, M and I are separately short for Category, Gender, Age, Education, Occasion, Position, Marriage and Income.). 


\section{Insert Table 4 here}

\section{Insert Table 5 here}

\section{The evaluation model of consumer credit}

\subsection{The theory basis of fisher discrimination}

The basic ideal of Fisher discrimination is to project the multi-dimensional data onto certain direction. The principle of projection is to separate the general as far as possible. The discrimination function is determined according to the principle that the distance between categories is largest and the distance in categories is smallest. Then the type of samples is determined by the linear discrimination equation. Divided by the discrimination equation, the same samples are centered while the different samples are discrete. This paper uses Fisher discrimination II.

(1) The solution of Fisher discrimination II equation

Assuming the samples are divided into $\mathrm{A}$ and $\mathrm{B}, n_{1}$ and $n_{2}$ are separately represent the numbers of sample A and sample B. the new discrimination equation is

$$
y=c_{1} x_{1}+c_{2} x_{2}+\ldots+c_{p} x_{p}
$$

$K$ represents the serial number of the variable. The centers of the A and B are separately:

$$
\begin{aligned}
& \overline{y_{k}(A)}=\frac{1}{n_{1}} \sum_{t=1}^{n_{1}} X_{k t}(A) \\
& \overline{y_{k}(B)}=\frac{1}{n_{2}} \sum_{t=1}^{n_{2}} X_{k t}(B)
\end{aligned}
$$

According to the basic ideal of Fisher discrimination, we should firstly determine how to express the distance between categories and the distance in categories. Then we use square between categories and $Q$ to represent the distance between categories and square in categories and $F$ to represent the distance in categories. The equations are showed as follows:

$$
\begin{gathered}
Q=[\overline{y(A)}-\overline{y(B)}]^{2} \\
F=\sum_{t=1}^{n_{1}}\left[y_{t}(A)-\overline{y(A)}\right]^{2}+\sum_{t=1}^{n_{2}}\left[y_{t}(B)-\overline{y(B)}\right]^{2}
\end{gathered}
$$

According to the basic idea of Fisher discrimination, we use the mathematical formulas to make the difference between extern-categories discrimination equation great and that between inner-categories discrimination equation small. Here we use $I$ (the ratio that square between categories and $Q$ to $F$ ). According to the maximum principle in differential, we make $I=Q / F$ for the partial differential and then make it equal 0 . The equations are showed as follows:

$$
\frac{\partial I}{\partial C_{k}}=\frac{F \frac{\partial Q}{\partial C_{k}}-Q \frac{\partial F}{\partial C_{k}}}{F^{2}}=0
$$

We make the discrimination function into the partial differential equation and obtain: 


$$
\begin{gathered}
\left\{\begin{array}{l}
s_{11} c_{1}+s_{12} c_{2}+\ldots+s_{1 m} c_{m}=d_{1} \\
s_{21} c_{1}+s_{22} c_{2}+\ldots+s_{2 m} c_{m}=d_{2} \\
\ldots \ldots \ldots \ldots \ldots \ldots \ldots \ldots \ldots \ldots \ldots \ldots \ldots
\end{array},\right. \text { and } \\
s_{m 1} c_{1}+s_{m 2} c_{2}+\ldots+s_{m m} c_{m}=d_{m} \\
s_{k l}=\sum_{t=1}^{n_{1}}\left[x_{k t}(A)-\overline{x_{k}(A)}\right]\left[x_{l t}(A)-\overline{x_{l}(A)}\right]+\sum_{t=1}^{n_{2}}\left[x_{k t}(B)-\overline{x_{k}(B)}\right]\left[x_{l t}(B)-\overline{x_{l}(B)}\right] \\
d_{k}=\overline{x_{k}(A)}-\overline{x_{k}(B)}
\end{gathered}
$$

We adapt the equations into the matrix:

$$
\begin{gathered}
S * C=D, \quad C=S^{-1} d \\
S=\left(\begin{array}{c}
s_{11} s_{12} \ldots s_{1 m} \\
s_{21} s_{22} \ldots s_{2 m} \\
\ldots \ldots \ldots \ldots \ldots \\
s_{m 1} s_{m 2} \ldots s_{m m}
\end{array}\right), C=\left(\begin{array}{l}
c_{1} \\
c_{2} \\
\ldots \\
c_{m}
\end{array}\right), d=\left(\begin{array}{l}
d_{1} \\
d_{2} \\
\ldots \\
d_{m}
\end{array}\right)
\end{gathered}
$$

Finally we make the sample data into the above equations to do the solution and we can obtain a group of coefficient values of the equation $y=c_{1} x_{1}+c_{2} x_{2}+\cdots+c_{p} x_{p}$.

(2) Classifying sample discrimination

To use the discrimination equation to classify the samples, we should firstly construct the threshold $y_{c}$ :

$$
y_{c}=\frac{n_{1} \overline{y(A)}+n_{2} \overline{y(B)}}{n_{1}+n_{2}}=\frac{\sum_{t=1}^{n_{1}} y_{t}(A)+\sum_{t=1}^{n_{2}} y_{t}(B)}{n_{1}+n_{2}}
$$

If $\overline{y(A)}>\overline{y(B)}$ and $y>y_{c}$, category A will appear, otherwise category B will.

If $\overline{y(A)}<\overline{y(B)}$ and $y>y_{c}$, otherwise category B will appear, otherwise category A will.

\subsection{The basic steps of Fisher discrimination analysis}

The credit analysis of Fisher discrimination has four steps:

(1) Classify the original data and achieve the research on the general category of consumer credit;

(2) Analyze the category of the known sample and the record of credit loss and determine whether the sample category has the distinct influence on the lack of credit. If it pass test, we can obtain the estimate of credit loss probability;

(3) Based on the result of the analysis of classifying, do the Fisher discrimination analysis and obtain the discrimination function;

(4) Make the samples into the discrimination function, determine the category of sample according to the discriminating principle, divide the criteria by the known level of consumer credit and determine the credit level of the consumer.

\section{An empirical study}

According to the scoring result of consumer credit indexes, we use the SPSS 12.0 to do the solution and the result is showed as Table 6.

\section{Insert Table 6 here}


From above table we can obtain the sample total is 40 and the valid sample is 40 .

\section{Insert Table 7 here}

From above table we can obtain the result of classifying statistics including mean, variance, unweighted weight and weighed weight and the category 1 represents the consumer of good credit that the mean of education is 4.15 and the variance is 0.671 .

\section{Insert Table 8 here}

From above table we can see the result that test whether the mean of the same variable is the same. We can obtain the significant level of age, education, occasion, position and income is 0.000 , which is far less than the popular confidence level 0.05 . It shows that the mean of age, education, occasion, position and income of different category are all different.

\section{Insert Table 9 here}

From above table we can see the first step is to enter the variable education, the second step is to enter the variable occasion and the third step is to enter the variable position. The statistics value in the column of Extract $\mathrm{F}$ is the ratio of Variable Square to error square. The bigger the value, the smaller the value of Sig. when the value of Sig. is smallest, its corresponding variable is entered into the discrimination equation. From the result we can see the stepwise in this example eliminates the variables of gender, age, marriage and income. Only education, occasion and position are entered into the discrimination equation.

\section{Insert Table 10 here}

Table 10 shows the condition of priori probability of each category. Because this paper uses the equal probability and divides the samples into 2 categories, the priori probability of each category is 0.5 .

\section{Insert Table 11 here}

We can get the coefficients from above table and use the data in above table to directly get the discrimination equation. We make a certain sample into the equation to calculate the score of each category, and then tell the category by the score and compare the score. The sample belongs to the bigger one.

The equation of good credit is: $y_{1}=7.983 *$ education $+5.526 *$ occasion $+2.856 *$ position- 34.927

The equation of good credit is: $y_{2}=3.839 *$ education $+2.564 *$ occasion $+0.752 *$ position- 7.340

\section{Insert Table 12 here}

According to the setting of the discrimination analysis, it can only output the discriminating analysis statistics of the first 10 samples. The "Case number" represents the number of samples; the "Actual Group" represents the actual category of each sample; the "Predicted Group" in the column of "Highest Group" represents the most likely category; the "Group" in the column of "Second Highest Group" represents the second most likely category.

\section{Insert Table 13 here}

The table shows the sample numbers of correct classification, ones of wrong classification and the rate of wrong judgment. It also cross-validates the sample numbers of correct classification, ones of wrong classification and the rate of wrong judgment. The result of the correct classification of which all the samples construct the discrimination equation is that the rate of wrong judgment in good credit is $0 \%$ and the one in bad credit is $0 \%$. The result of the correct classification that cross-validates the discrimination equation is that the rate of wrong judgment in good credit is $0 \%$ and the one in bad credit is $0 \%$.

A new variable is generated named Dis-1 from the original data in the data editing window. Record the result of discriminating classification of each sample generated by the discriminating equation and we can get the conclusion that the result of discriminating classification is the same as the actual category.

\section{Conclusion}

To evaluate the consumer credit will help the society evaluate the level of consumer credit, help enterprises reduce the cost of the returns reverse logistics and improve the operational efficiency of reverse logistics and the quality of consumers.

\section{References}

Abdelkader Sbihi \& Richard W. Eglese. (2007). Reverse Logistics-the least used differentiator. UPS Supply Chain Solutions.

H.M. Blance, H.A. Fleuren \& H. R.Krikke. (2004). Redesign of a Recycling System for LPG-tanks. OR Spectrum.

Patrick Beullens. (2004). Reverse Logistics in Effective Recovery of Products from Waste Materials. Reviews in Environment Science and Biotechnology, 3:283-300.

$\mathrm{Xu}$, Xiaohua \& Pan, Xuhua. (2006). The psychology, causes and countermeasures of consumers' dishonest consumption. 
Modern shopping malls.

Yang, Li, Song, Li, et al. (2006). The statistical model methods of credit scoring. Statistics and decision-making.

Zhang, Wenbo \& Chen, Hongyan. (2006). The statistics analysis of practical data and SPSS 12.0. Posts \& Telecom Press.

Table 1 . The index system of consumer credit evaluation

\begin{tabular}{|l|c|c|}
\hline \multirow{4}{*}{ Consumer credit } & \multirow{4}{*}{ Qualitative factors } & gender \\
\cline { 3 - 3 } & & education \\
\cline { 3 - 3 } & & occasion \\
\cline { 3 - 3 } & & position \\
\cline { 2 - 3 } & Quantitative & marriage \\
\cline { 2 - 3 } & factors & age \\
\cline { 2 - 3 } & & income \\
\hline
\end{tabular}

Table 2. Consumer credit index scoring list

\begin{tabular}{|c|c|c|}
\hline $\begin{array}{c}\text { Evaluation } \\
\text { indexes }\end{array}$ & Evaluation contents & Score \\
\hline gender & $\begin{array}{c}\text { male } \\
\text { female }\end{array}$ & $\begin{array}{l}3 \\
2\end{array}$ \\
\hline age & $\begin{array}{c}\text { Below } 25 \\
25-35 \\
36-45 \\
\text { Above } 45\end{array}$ & $\begin{array}{l}1 \\
2 \\
3 \\
4\end{array}$ \\
\hline education & $\begin{array}{c}\text { master } \\
\text { undergraduate } \\
\text { college } \\
\text { high school (secondary) } \\
\text { less than junior }\end{array}$ & $\begin{array}{l}5 \\
4 \\
3 \\
2 \\
1\end{array}$ \\
\hline occasion & $\begin{array}{l}\text { Information technology, high-tech, finance, education, energy monopolies, corporations, } \\
\text { hospitals, organizations } \\
\text { Press, publishing, technology-intensive manufacturing } \\
\text { Trade, consulting, architecture } \\
\text { Traffic, transport, tourism } \\
\text { technology-lower industry, catering, construction }\end{array}$ & $\begin{array}{l}5 \\
4 \\
3 \\
2 \\
1\end{array}$ \\
\hline position & $\begin{array}{c}\text { R \& D, high-level managers, teachers, doctors and other emerging post } \\
\text { Middle managers, technicians } \\
\text { Sales, general workers } \\
\text { others }\end{array}$ & $\begin{array}{l}5 \\
4 \\
2 \\
0\end{array}$ \\
\hline marriage & $\begin{array}{l}\text { married } \\
\text { single }\end{array}$ & $\begin{array}{l}3 \\
2\end{array}$ \\
\hline income & $\begin{array}{c}\leq 1000 \text { Yuan } \\
1000 \text { Yuan }-3000 \text { Yuan (including 3000) } \\
3000 \text { Yuan -5000 Yuan (including 5000) } \\
5000 \text { Yuan-8000 Yuan (including 8000) } \\
\geq 8000 \text { Yuan }\end{array}$ & $\begin{array}{l}1 \\
2 \\
3 \\
4 \\
5\end{array}$ \\
\hline
\end{tabular}


Table 3. The table of consumer credit questionnaire

\begin{tabular}{|c|c|c|c|c|c|c|c|c|}
\hline No. & $\mathrm{C}$ & gender & age & education & occasion & position & $\mathrm{M}$ & $\mathrm{I}$ \\
\hline 1 & 1 & female & 37 & undergraduate & press & High-manager & married & 5500 \\
\hline 2 & 1 & male & 29 & undergraduate & petrochemical & technician & single & 3600 \\
\hline 3 & 2 & male & 31 & High school & food-manufacturing & worker & single & 1000 \\
\hline 4 & 1 & female & 48 & undergraduate & hospital & doctor & married & 4000 \\
\hline 5 & 2 & female & 23 & junior & restaurants & waitress & married & 850 \\
\hline 6 & 2 & male & 26 & High school & construction & worker & single & 1800 \\
\hline 7 & 1 & male & 41 & graduate & metallurgical-manufacturing & engineer & married & 8700 \\
\hline 8 & 1 & female & 46 & undergraduate & trade & Middle-manager & single & 4100 \\
\hline 9 & 2 & female & 24 & secondary & transport & worker & married & 900 \\
\hline 10 & 2 & male & 27 & college & trade & sale & single & 1500 \\
\hline 11 & 2 & female & 30 & High school & Textile manufacturing & worker & married & 1000 \\
\hline 12 & 1 & male & 36 & undergraduate & Information technology & R\&D & single & 6000 \\
\hline 13 & 1 & female & 39 & Graduate & press & editor & married & 3500 \\
\hline 14 & 2 & female & 25 & High school & Tourism & record & single & 2000 \\
\hline 15 & 2 & female & 20 & secondary & Restaurants & Cash register & single & 950 \\
\hline 16 & 1 & male & 49 & undergraduate & consulting & analyst & married & 4800 \\
\hline 17 & 1 & female & 26 & undergraduate & Electronic manufacturing & Middle-manager & single & 3200 \\
\hline 18 & 1 & male & 42 & Graduate & petrochemical & worker & married & 3000 \\
\hline 19 & 2 & male & 19 & junior & construction & Temporary-worker & single & 800 \\
\hline 20 & 1 & female & 37 & undergraduate & education & executive & single & 6000 \\
\hline 21 & 2 & female & 18 & junior & Construction-installation & worker & single & 1100 \\
\hline 22 & 2 & female & 30 & High school & traffic & worker & married & 1000 \\
\hline 23 & 1 & male & 44 & graduate & Finance & High-manager & married & 8800 \\
\hline 24 & 1 & female & 32 & college & publishing & Middle-manager & married & 3500 \\
\hline 25 & 2 & female & 26 & college & cosmetics & sale & single & 2800 \\
\hline 26 & 2 & female & 39 & High school & restaurants & Waitress & married & 1000 \\
\hline 27 & 1 & male & 46 & undergraduate & petrochemical & High-manager & single & 10000 \\
\hline 28 & 1 & female & 38 & graduate & agency & section & married & 4800 \\
\hline 29 & 1 & male & 40 & college & consulting & Analyst & married & 3700 \\
\hline 30 & 1 & male & 29 & undergraduate & Equipment-manufacturing & Sale & single & 5200 \\
\hline 31 & 2 & male & 22 & High school & traffic & Worker & single & 1000 \\
\hline 32 & 1 & female & 37 & college & Electronic-manufacturing & Technician & married & 3600 \\
\hline 33 & 2 & female & 24 & primary & agriculture & farming & married & 600 \\
\hline 34 & 2 & female & 25 & college & transport & Worker & married & 2000 \\
\hline 35 & 2 & male & 41 & High school & construction & Worker & married & 1800 \\
\hline 36 & 2 & female & 22 & secondary & department & Sale & single & 1000 \\
\hline 37 & 1 & male & 43 & undergraduate & Electronic power & Engineer & married & 7000 \\
\hline 38 & 1 & female & 52 & graduate & education & executive & married & 3500 \\
\hline 39 & 2 & female & 27 & junior & consulting & Worker & single & 1400 \\
\hline 40 & 2 & male & 36 & High school & manufacturing & worker & single & 1000 \\
\hline
\end{tabular}


Table 4. The result of consumer credit score

\begin{tabular}{|c|c|c|c|c|c|c|c|c|c|c|c|c|c|c|c|c|c|c|c|c|}
\hline No & 1 & 2 & 3 & 4 & 5 & 6 & 7 & 8 & 9 & 10 & 11 & 12 & 13 & 14 & 15 & 16 & 17 & 18 & 19 & 20 \\
\hline $\mathrm{C}$ & 1 & 1 & 2 & 1 & 2 & 2 & 1 & 1 & 2 & 2 & 2 & 1 & 1 & 2 & 2 & 1 & 1 & 1 & 2 & 1 \\
\hline $\mathrm{G}$ & 2 & 3 & 3 & 2 & 2 & 3 & 3 & 2 & 2 & 3 & 2 & 3 & 2 & 2 & 2 & 3 & 2 & 3 & 3 & 2 \\
\hline $\mathrm{A}$ & 3 & 2 & 2 & 4 & 1 & 2 & 3 & 4 & 1 & 2 & 2 & 3 & 3 & 2 & 1 & 4 & 2 & 3 & 1 & 3 \\
\hline $\mathrm{E}$ & 4 & 4 & 2 & 4 & 1 & 2 & 5 & 4 & 2 & 3 & 2 & 5 & 4 & 2 & 2 & 4 & 4 & 5 & 1 & 4 \\
\hline $\mathrm{O}$ & 4 & 5 & 1 & 5 & 1 & 3 & 4 & 3 & 2 & 3 & 1 & 5 & 4 & 2 & 1 & 3 & 4 & 5 & 3 & 5 \\
\hline $\mathrm{P}$ & 5 & 4 & 2 & 4 & 0 & 2 & 5 & 4 & 2 & 2 & 2 & 4 & 5 & 2 & 0 & 4 & 4 & 2 & 0 & 5 \\
\hline $\mathrm{M}$ & 3 & 2 & 2 & 3 & 3 & 2 & 3 & 2 & 3 & 2 & 3 & 2 & 3 & 2 & 2 & 3 & 2 & 3 & 2 & 2 \\
\hline $\mathrm{I}$ & 4 & 3 & 1 & 3 & 1 & 2 & 5 & 3 & 1 & 2 & 1 & 4 & 3 & 2 & 1 & 3 & 3 & 2 & 1 & 4 \\
\hline
\end{tabular}

Table 5. Table 4 continuing

\begin{tabular}{|l|l|l|l|l|l|l|l|l|l|l|l|l|l|l|l|l|l|l|l|}
\hline 21 & 22 & 23 & 24 & 25 & 26 & 27 & 28 & 29 & 30 & 31 & 32 & 33 & 34 & 35 & 36 & 37 & 38 & 39 & 40 \\
\hline 2 & 2 & 1 & 1 & 2 & 2 & 1 & 1 & 1 & 1 & 2 & 1 & 2 & 2 & 2 & 2 & 1 & 1 & 2 & 2 \\
\hline 2 & 2 & 3 & 2 & 2 & 2 & 3 & 2 & 3 & 3 & 3 & 2 & 2 & 2 & 3 & 2 & 3 & 2 & 2 & 3 \\
\hline 1 & 2 & 3 & 2 & 2 & 3 & 4 & 3 & 3 & 2 & 1 & 3 & 1 & 2 & 3 & 1 & 3 & 4 & 2 & 3 \\
\hline 1 & 2 & 5 & 3 & 3 & 2 & 4 & 5 & 3 & 4 & 2 & 3 & 1 & 3 & 2 & 2 & 5 & 4 & 1 & 2 \\
\hline 3 & 2 & 5 & 4 & 1 & 1 & 5 & 4 & 3 & 4 & 2 & 4 & 1 & 2 & 3 & 2 & 4 & 5 & 3 & 1 \\
\hline 2 & 2 & 5 & 4 & 2 & 0 & 5 & 4 & 4 & 2 & 2 & 4 & 0 & 2 & 2 & 2 & 5 & 4 & 2 & 2 \\
\hline 2 & 3 & 3 & 3 & 2 & 3 & 2 & 3 & 3 & 2 & 2 & 3 & 3 & 3 & 3 & 2 & 3 & 3 & 2 & 2 \\
\hline 2 & 1 & 5 & 3 & 2 & 1 & 5 & 3 & 3 & 4 & 1 & 3 & 1 & 2 & 2 & 1 & 4 & 3 & 2 & 1 \\
\hline
\end{tabular}

Table 6. The data of discriminating samples

\begin{tabular}{|c|c|c|c|}
\hline \multicolumn{2}{|c|}{ Unweighted Cases } & N & Percent \\
\hline & Valid & 40 & 100.0 \\
\hline \multirow{2}{*}{ Excluded } & Missing or out-of-range group codes & 0 & .0 \\
\hline \multirow{2}{*}{} & At least one missing discriminating variable & 0 & .0 \\
\hline & $\begin{array}{c}\text { Both missing or out-of-range group codes and at } \\
\text { least one missing discriminating variable }\end{array}$ & 0 & .0 \\
\hline & Total & 0 & 100.0 \\
\hline
\end{tabular}


Table 7. The result of classification statistics

\begin{tabular}{|c|c|c|c|c|c|}
\hline \multirow{2}{*}{\multicolumn{2}{|c|}{ classification }} & \multirow{3}{*}{$\begin{array}{c}\text { mean } \\
2.50\end{array}$} & \multirow{3}{*}{$\begin{array}{c}\text { Variance } \\
.513\end{array}$} & \multicolumn{2}{|c|}{ weight } \\
\hline & & & & \multirow{2}{*}{$\begin{array}{c}\text { Unweighted weight } \\
20\end{array}$} & \multirow{2}{*}{$\frac{\text { Weighted weigh }}{20.000}$} \\
\hline 1 & Gender & & & & \\
\hline & Age & 3.05 & .686 & 20 & 20.000 \\
\hline & Education & 4.15 & .671 & 20 & 20.000 \\
\hline & Occasion & 4.25 & .716 & 20 & 20.000 \\
\hline & Position & 4.15 & .875 & 20 & 20.000 \\
\hline & Marriage & 2.65 & .489 & 20 & 20.000 \\
\hline & Income & 3.50 & .827 & 20 & 20.000 \\
\hline \multirow[t]{7}{*}{2} & Gender & 2.35 & .489 & 20 & 20.000 \\
\hline & Age & 1.75 & .716 & 20 & 20.000 \\
\hline & Education & 1.90 & .641 & 20 & 20.000 \\
\hline & Occasion & 1.90 & .852 & 20 & 20.000 \\
\hline & Position & 1.50 & .889 & 20 & 20.000 \\
\hline & Marriage & 2.40 & .503 & 20 & 20.000 \\
\hline & Income & 1.40 & .503 & 20 & 20.000 \\
\hline \multirow[t]{7}{*}{ Total } & Gender & 2.42 & .501 & 40 & 40.000 \\
\hline & Age & 2.40 & .955 & 40 & 40.000 \\
\hline & Education & 3.03 & 1.310 & 40 & 40.000 \\
\hline & Occasion & 3.08 & 1.421 & 40 & 40.000 \\
\hline & Position & 2.83 & 1.599 & 40 & 40.000 \\
\hline & Marriage & 2.53 & .506 & 40 & 40.000 \\
\hline & Income & 2.45 & 1.260 & 40 & 40.000 \\
\hline
\end{tabular}

Table 8 . The variance analysis of univariate

\begin{tabular}{c|c|c|c|c}
\hline & $\mathrm{F}$ & $\mathrm{df} 1$ & $\mathrm{df2}$ & Sig. \\
\hline Gender & .895 & 1 & 38 & .350 \\
\hline Age & 34.342 & 1 & 38 & .000 \\
\hline Education & 117.661 & 1 & 38 & .000 \\
\hline Occasion & 89.110 & 1 & 38 & .000 \\
\hline Position & 90.306 & 1 & 38 & .000 \\
\hline Marriage & 2.540 & 1 & 38 & .000 \\
\hline Income & 94.146 & 1 & 38 &
\end{tabular}

Table 9. Stepwise discrimination variable enter/ eliminate list

\begin{tabular}{|c|c|c|c|c|c|c|c|c|}
\hline \multirow{3}{*}{ Step } & \multirow{3}{*}{ Entered } & \multicolumn{7}{|c|}{ Wilks'Lambda } \\
\hline & & \multirow{2}{*}{ df1 } & \multirow{2}{*}{$\mathrm{df} 2$} & \multirow{2}{*}{ df3 } & \multicolumn{4}{|c|}{ Exact $F$} \\
\hline & & & & & Statistic & df1 & $\mathrm{df} 2$ & Sig. \\
\hline 1 & education & 1 & 1 & 38.000 & 117.661 & 1 & 38.000 & .000 \\
\hline 2 & occasion & 2 & 1 & 38.000 & 91.245 & 2 & 37.000 & .000 \\
\hline 3 & position & 3 & 1 & 38.000 & 69.028 & 3 & 36.000 & .000 \\
\hline
\end{tabular}


Vol. 4, No. 2

Table 10. Priori probability

\begin{tabular}{c|c|c|c}
\hline \multirow{2}{*}{ category } & \multirow{2}{*}{ Prior } & \multicolumn{2}{|c}{ Cases Used in Analysis } \\
\cline { 3 - 4 } & & Unweighted & Weighted \\
\hline 1 & .500 & 20 & 20.000 \\
\hline 2 & .500 & 20 & 20.000 \\
\hline Total & 1.000 & 40 & 40.000 \\
\hline
\end{tabular}

Table 11. The coefficients of Fisher linear discrimination equation

\begin{tabular}{c|c|c}
\hline \multirow{2}{*}{} & \multicolumn{2}{|c}{ category } \\
\cline { 2 - 3 } & 1 & 2 \\
\hline education & 7.983 & 3.839 \\
\hline occasion & 5.526 & 2.564 \\
\hline position & 2.856 & .752 \\
\hline (Constant) & -34.927 & -7.340 \\
\hline
\end{tabular}

Table 12. The statistics list of sample classification

\begin{tabular}{|c|c|c|c|c|c|c|c|c|}
\hline \multirow{3}{*}{\multicolumn{2}{|c|}{ Case Number }} & \multirow{4}{*}{$\begin{array}{c}\text { Actual } \\
\text { Group } \\
1\end{array}$} & \multicolumn{4}{|c|}{ Highest Group } & \multicolumn{2}{|c|}{ Second Highest Group } \\
\hline & & & \multirow{3}{*}{$\begin{array}{c}\begin{array}{c}\text { Predicted } \\
\text { Group }\end{array} \\
1\end{array}$} & \multicolumn{2}{|c|}{$P(D>d \mid G=g)$} & \multirow{3}{*}{$\begin{array}{c}\mathrm{P}(\mathrm{G}=\mathrm{g} \\
\mid \mathrm{D}=\mathrm{d}) \\
1.000000\end{array}$} & \multirow{3}{*}{$\begin{array}{c}\text { Group } \\
2\end{array}$} & \multirow{3}{*}{$\begin{array}{c}\mathrm{P}(\mathrm{G}=\mathrm{g} \\
\mid \mathrm{D}=\mathrm{d}) \\
.000\end{array}$} \\
\hline & & & & $\mathrm{p}$ & $\mathrm{df}$ & & & \\
\hline \multirow[t]{10}{*}{ Original } & 1 & & & .927 & 1 & & & \\
\hline & 2 & 1 & 1 & .783 & 1 & 1.000 & 2 & .000 \\
\hline & 3 & 2 & 2 & .797 & 1 & 1.000 & 1 & .000 \\
\hline & 4 & 1 & 1 & .783 & 1 & 1.000 & 2 & .000 \\
\hline & 5 & 2 & 2 & .041 & 1 & 1.000 & 1 & .000 \\
\hline & 6 & 2 & 2 & .312 & 1 & .998 & 1 & .002 \\
\hline & 7 & 1 & 1 & .328 & 1 & 1.000 & 2 & .000 \\
\hline & 8 & 1 & 1 & .321 & 1 & .998 & 2 & .002 \\
\hline & 9 & 2 & 2 & .706 & 1 & 1.000 & 1 & .000 \\
\hline & 10 & 2 & 2 & .058 & 1 & .887 & 1 & .113 \\
\hline
\end{tabular}


Table 13. The statistics list of classification result

\begin{tabular}{|c|c|c|c|c|c|}
\hline \multirow{2}{*}{\multicolumn{3}{|c|}{ category }} & \multicolumn{2}{|c|}{ Predicted Group Membership } & \multirow{3}{*}{$\begin{array}{c}\text { Total } \\
20\end{array}$} \\
\hline & & & 1 & 2 & \\
\hline \multirow{4}{*}{ Original } & \multirow{2}{*}{ Count } & 1 & 20 & 0 & \\
\hline & & 2 & 0 & 20 & 20 \\
\hline & \multirow{2}{*}{$\%$} & 1 & 100.0 & .0 & 100.0 \\
\hline & & 2 & .0 & 100.0 & 100.0 \\
\hline \multirow{4}{*}{ Cross-Validated } & \multirow{2}{*}{ Count } & 1 & 20 & 0 & 20 \\
\hline & & 2 & 0 & 20 & 20 \\
\hline & \multirow{2}{*}{$\%$} & 1 & 100.0 & .0 & 100.0 \\
\hline & & 2 & .0 & 100.0 & 100.0 \\
\hline
\end{tabular}

